\title{
ANALYZING THE MEDIATING EFFECT OF LEARNING ORIENTATION ON THE RELATIONSHIP OF MARKET ORIENTATION AND COMPANY PERFORMANCE IN TIMES OF TURBULENCE
}

\author{
Niels Becker, RWTH University of Aachen, Germany \\ Malte Brettel, RWTH University of Aachen, Germany
}

\begin{abstract}
The marketing concept postulates that to achieve a competitive advantage firms should identify and satisfy customer needs more effectively than their competitors (Day 1994) and much of the extensive market orientation literature examines the extent to which firms adhere to this (Kohli et al. 1990, Narver et al. 1990). Much research has investigated the direct impact of market orientation on company performance and the majority of these studies indicate that market orientation is positively associated with company performance (Cano et al. 2004, Ellis 2006, Vieira 2010). Only few studies display negative or nonsignificant findings (Agarwal et al. 2003, Bhuian 1997, Sandvik et al. 2003). However, despite these relatively consistent, positive findings, there is little understanding of how market orientation should be deployed to achieve a competitive advantage (Han et al. 1998, Morgan et al. 2009).
\end{abstract}

In this context scholars suggest that market orientation must be accompanied by a strong learning orientation (Baker et al. 1999, Slater et al. 1995), as it enables firms to maintain a long-term competitive advantage by continuously improving the processing of market information. It helps companies to question long standing market assumptions or beliefs and to manage disruptive change (Day 1994, Christensen 1997). Moreover, as Dickson (1996) postulates, a strong market orientation can be readily copied, but the learning environment that organizes and translates the output of these behaviors into a comparative advantage cannot. Notably, in dynamic market environments, which are characterized by the high rate of change in the composition of customers and their preferences, the ability to learn faster than competitors might be the only source of competitive advantage (DeGeus 1988), as products and services are likely to have to be continuously modified to cater to customers' changing preferences. In particular, a strong learning orientation may facilitate required changes in the market offering and finally lead to improved performance (Fiol et al. 1985).

Though researchers have proposed that market orientation should be accompanied by a strong learning orientation, only few studies have empirically explored this relationship (Ali et al. 2010, Grinstein 2008a). Moreover, the impact of environmental conditions on this relationship has remained largely unaddressed (Cano et al. 2004, Lin et al. 2008, Santos-Vijande et al. 2005). Accordingly, the present paper investigates the direct effect of market and learning orientation on company performance. In addition, the mediating effect of learning orientation on the market orientation-performance link is examined. It is argued that market orientation provides the company with market information, on which learning can occur (Farrell 2000). Finally, the moderating effect of market dynamism on these relationships is investigated. In more dynamic market environments the market and learning orientation interface is assumed to be more important (Slater et al. 1995).

To conduct the research a cross-sectional online survey was conducted. The sample was obtained from the German Chamber of Industry and Commerce and covered companies in 12 different industries. In spring 2010, 290 qualified responses from managing directors or heads of marketing were received. Partial least squares, a broadly accepted variance-based structural equation modeling technique, was used to evaluate the proposed theoretical model (Wold 1985). It has already been used in studies similar to this one (O'Cass et al. 2007, Voola et al. 2010).

The empirical findings suggest that there is no direct, but an indirect effect of market orientation on company performance. Learning orientation mediates the relationship between market orientation and company performance. Hence, it can be concluded that in order for a company to achieve a superior performance, market orientation should be combined with a strong learning orientation. Market oriented companies are exceptional in gathering market information relevant to the company. However, they run the risk to limit their learning to current and expressed needs of their customers (La et al. 2004, Slater et al. 1995). Learning oriented companies challenge this market information and can assess effectively, how to act on it. They acknowledge that at times not all market information is useful and therefore firms sometimes need to unlearn. In addition, with regard to the moderating effect of market dynamism the results indicate no clear findings. Market dynamism positively moderates the relationship between market and learning orientation, but does not affect the relationship of learning orientation and company performance.

References available upon request 